\title{
Roberto Bolaño: El resplandor de la so mbra. La escritura del mal y la historia
}

\section{ANIUSKA GONZÁLEZ*}

Resumen

Detrás del mal en la palabra literaria de Roberto Bolaño está la historia. Durante los siglos de existencia humana, el mal, además de aparecer como objeto de representación y como definición filosófica, ha generado sus propios símbolos que actúan, en mayor o menor escala, con comunida des deindividuos y sobre ellas, se despliega. En este sentido, el ensayo "Roberto Bolaño: El resplandor de la sombra. La escritura del mal y la historia" pretende leer parte de la relación entre el mal y su representación histórica en la narrativa de este autor chileno; ese mal que, dentro de la historia, la atrae esencialmente como experiencia. Es un cuerpo narrativo tejido obsesivamente con una palabra sutil, pero envilecida hasta una gradación insostenible, y queexplora el aniquilamiento moral de una sociedad durante la época de una dictadura.

Palabras daves: Mal, historia, dictadura, indiferencia moral.

ABSTRACT

Behind theevil in Roberto Bolaño's literary word ishistory. During the centuries of human existence, evil, besides appearing as an object of representation and as a philosophical definition, has generated its own symbols that act, to a greater or lesser degree, in communities of individuals, spreading over them. In this sense, theessay "Roberto Bolaño: TheSplendor of theShadow. TheWriting of Evil and History" seeks to read part of the relationship between evil and its historical representation in this Chilean author's narrative; the evil that from inside history is attractive essentially as experience. It is a narrative body knit obsessively with a subtle word, but debased to the point of an untenable gradation that explores the moral annihilation of a society during the time of a dictatorship.

Keywords: Evil-H istory, dictatorship, moral indifference.

Recibido: 23.09.2003. Aprobado: 22.12.2003.

*Profesora de la Universidad Simón Bolívar, de Caracas, Venezuela. M agíster en Literatura Latinoamericana y Doctorando en Letras. Ha publicado El concilio delasfábulas (poesía, 1993), Antonio Santoro, memorias de un emigrante (biografía, 1994), Poetas cubanos actuales (1995), Palabra de la muerte (poesía, 1998, 1999) y Las iniciales del tiempo (2001). Es subdirectora de la revista literaria Ateneo y de la Colección Literaria Ateneo de Los Teques. E-mail: gdaniuska@hotmail.com y dgonzalez@usb.ve 


\section{INTRODUCCION}

N LA Historia del diablo (2002), Robert Muchembled, su autor, interpreta el vínculo de la sociedad con la producción de imaginarios llamados a perpetuarla, una cultura y una historia ${ }^{1}$ que "teje[ $n$ ] en torno a sus miembros redes de relación constituidas por símbolos poderosos entrecruzados" (19). Sobre este sentido, durante todos los sigl os de existencia humana, el mal, además de contextualizarse como objeto de representación y como definición reflexiva o filosófica, genera su propia simbología que interactúa, en mayor o menor escala, con comunidades de individuos y sobre ella, se despliega.

Toda época ha sabido del desboque del mal, o, al menos, delasinstancias que ha denominado bajo este epíteto. A su al rededor, una parte de la sociedad le ha creado estratos que lo señalan (y lo exorcizan) como lo punible, lo que ha de rechazarse. Y así lo asienta históricamente. Al igual que la condición humana individual, la sociedad-ese espacio sobreel quecomulgan los intereses, la integración y la subordinación entre los individuos- comparte un lado de sombras y oscuridad, con otro resplandeciente, deluz y vigorosa claridad. De esta forma, se van superponiendo, en la madeja histórico-social, la cultura, las guerras, las circunstancias éticas o morales, la política, la irracionalidad o la lucidez... Amal gamado todo, se puede escrutar una sociedad por este carácter poliforme, casi siempre paralelo, de sus discursos y de sus prácticas, de su status y de su desarrollo gradual.

Por eso, esteensayo tratará de construir en la escritura de Roberto Bolaño (1953-2003), a través de un lenguaje² muy particular, la práctica histórica del mal.

"Refiero la historia bajo la perspectiva deacontecimiento "vivido en al guna región dela realidad" (White: 1992: 43) social; de elaboración y vivencia de la sociedad en tanto grupo o colectividad que ha logrado poseer un "referente primario" (63) de su propia actuación y cultura. Además y a pesar de las múltiples discusiones que esto ha generado en el debate histórico postmoderno, la escribo con mayúscula para marcarla como dispositivo generador de poder y control, como "simbolismo de [un] orden (...), de la dominación (...) de las jerarquías" (Bazcko: 1991: 18).

${ }^{2}$ Este texto forma parte de mi investigación doctoral, actual mente en proceso, sobre la narrativa de Roberto Bolaño. En este sentido, he puesto énfasis en queel autor elabora un lenguaje* del mal, un dispositivo discursivo que le da voz, además de la Historia como ejercicio del horror, a ciertos espacios irrepresentables, como el silencio, la fractura de sentidos... todos dentro del mal, por cierto, irrepresentable él mismo. Como explica Sergio Rojas en su ensayo "Cuerpo, lenguajey desaparición", recogido por Nelly Richard en Políticas y estéticas de la memoria (2000). "Lo que el lenguaje nombra adquiere el cuerpo de su nombre: el nombre es la forma" (178).

*O bviamente, desdeel punto de vista lingüístico, existe una diferencia entre lenguajey lengua, pero, a instancias de este trabajo, las utilizaréindistintamente, cobijándome en la acepción con las cuales Bajtín las cohesionó en “Problemas literarios y estéticos" (1986). Para él, ambas representan "una expresión viva surgida de manera consciente en un momento histórico específico en un medio socialmentedeterminado, (...) [quetropiezan] con los miles dehilos diagonales vivos-tejidos por la conciencia socioideológica alrededor del objeto de expresión dado- (...) [y] que en uno u otro grado son objetivados, mostrados" (105-145). 
Resulta complejo armar el mal a partir de este contexto. Demasiada carga ideológica sobre él, demasiados presupuestos. Históricamente, se le ha situado en un único lado, y allí se le encerró. En ese espacio, todavía se despereza. H ay un siglo XXI con cuadrículas del mal bien delimitadas: geográficas, económicas, políticas... ¿Q uién las cambia? No hacefalta un exorcista, porque se entiende que esa figura - Estados Unidos, quizá- se ha connotado ahora de otra manera: es quien señala, determina, al diablo. De ahí que nos encontremoscon el mal cara a cara, pues, como acotó Baudrillard, ha logrado metamorfosearse, aparecerse en todos los lugares inimaginables, como, por ejemplo,

... Jomeini, en el caso Rushdie...

Enfrentado al mundo entero, en una relación de fuerzas política, militar y económica totalmente negativa, el ayatollah dispone de una sola arma, inmaterial, pero que no está lejos de ser el arma absoluta: el principio del $\mathrm{Mal}$. Denegación de los valores occidentales de progreso, de racionalidad, de moral política, de democracia, etc. N egar el consenso universal sobre todas esas buenas cosas le confiere la energía del M al, la energía satánica del réprobo, el fulgor de la parte maldita. (...). En cambio, podemos comprobar la superioridad que eso le confiere sobre un Occidente donde en ningún lugar queda la posibilidad de nombrar el Mal (Baudrillard: 1997: 90-91) (Lo destacado en cursivas: D.G.).

A lo destacado en cursivas de la cita anterior me proponía llegar desde un principio. Al punto en quemiramosel mal como problemática histórica, hoy, más que nunca, le encajamos un conjunto de valoresque, para O ccidente y, por supuesto, para nosotros como sociedad dentro de él, representa la balanza, el medidor, de lo que se denomina el bien. A la larga, se produce el estallido: cuesta reconocer al mal porque se ha camuflado, y casi se parece a su antítesis, el bien.

Ya se desconocen hacia dónde fluctúan los valores del altruismo, de la bondad, tradicionalmente territorios del bien. Están en una práctica social inconexa, dislocada, "opaca y sin sentido que despliega ofuscación" (Arendt: 1992: 10). Se vive bajo el signo de la mezcla, y por eso, se acepta la estrategia del bien como mal, o, de éste como bien. Así, cabe todo.

En este sentido, las actual es guerras contra el terrorismo se nutren de tan compleja energía. Por un lado, Occidente despliega la fuerza para nombrar al mal y eliminarlo, lo curioso es que su cruzada se afirma, precisamente, sobre algunos elementos enquistados en la propia simbología del mal: el genocidio, la muerte, la destrucción... En fin, el Apocalipsis montado desde el "bien". Contrariamente, si no se ataca el terrorismo, éste avanzará (y de hecho ya lo hace) con su fanatismo suicida y violento, también abrevadero del mal - para nosotros, quedeclaro- . Pocas dudas, entonces, sobre esta fragilidad del límite entre el bien y el mal en nuestro tiempo. 


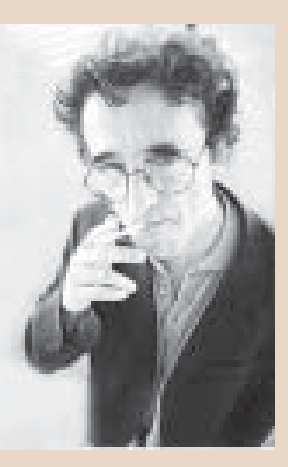

EN LA BOCA DEL LOBO: EL LENGUAJE DEL MAL Y LA HISTORIA

Deesta manera, el mal histórico en la escritura de Bolaño es un rayo potente que agrede sobre las historias y los personajes, sobreel contexto narrativo mismo. Como fractura - por separación- y, al unísono, como vínculo entre el lenguaje -esa lengua del mal- y el significado que tiene que ver con un sistema generador de representaciones e imágenes de la historia.

En al gunas delasnovelas de Bolaño - La literatura nazi en América (1996), Estrella distante (1996), Amuleto (1999) y N octurno deChile(2000)-, en esta lengua del mal queva creando, seestructuran los rompientes históricos más aterradores, las partículas implosivas que germinan como una aberración sobre la convivencia, el pathos que destruye y queda como huella histórica marcada. Hay una patología del escarnio social y de la deformación de las estructuras colectivas. Esa mirada se extiende desde representar la historia a partir del absurdo y la subversión, hasta inhabilitar -y contraponer o desdibujar- figuras y acontecimientos. No se trata de lograr ni siquiera un paralelo entre el hecho histórico y el literario, sino de dinamitar la historia - ¿para qué se cuenta, acaso, con la lengua del mal?- hasta hacerla, a veces, irreconocible.

La historia biográfica y anecdótica, que ocupa un lugar muy bajo dela escala, es una historia débil, que no contiene en sí misma su propia inteligibilidad, pues la alcanza solamente cuando sela transporta, en bloque, al seno de una historia más fuerte que ella (Lévi-Strauss: 1975: 378).

Limitándonos a esta reflexión de Lévi-Strauss en El pensamiento salvaje, cuando planteó su reticencia acerca de la trampa que tiende la historia a la literatura respecto a su representación, se observa que al hacerse materia de la escritura literaria, la situación histórica, ya debilitada por el ejercicio dela imaginación, tiene que levantarse sobre sus restos y deificarse como "una historia más fuerte que ella", más que su valor histórico en sí.

Así, los cuerpos textuales de las novelas antes mencionadas, tejidos obsesivamente con una palabra sutil, pero envilecida, exploran el aniquilamiento histórico de una sociedad, hasta tal grado "que (...) crispaba los nervios (...), [donde] Era necesario hacer cosas (las quefuera, cambiar de puesto un florero cinco veces en media hora, para no volverse loca)" (Bolaño: 1996 b: 48).

No se puedenegar: en Bolaño, tras la tiranía de la palabra, ésa dominada por una maligna rigidez interior, está la de la historia. Tiranía en el sentido de adueñarse del cauce de la estructura narrativa, del lenguaje como dispositivo discursivo, para drenarlos hacia acontecimientos totalitarios, hacia esas figuras que escribieron una historia particular, pero que no dejan de entretejerse con un universo general; o sea, transcribir lo más abyecto de la 
$\mathrm{H}$ istoria, sus zonas de sombras. Novelas complejas, en sus intenciones, en sus oscuridades. Demasiadas simbologías para atraparlas, también demasiada subversión sobre ellas. En conjunto, se trata de

representacionesimaginarias [que] son objetos de investigaciones, como las acciones visibles de los hombres. No se trata de una especie de velo global proveniente de los designios divinos, ni de un inconsciente colectivo en el sentido deJung, sino de un fenómeno colectivo muy real producido por los múltiples canales culturales que irrigan a una sociedad. Es una suerte de maquinaria oculta bajo la superficie delas cosas, poderosamenteactiva porque crea sistemas de explicación y también motiva tanto las acciones individuales como los comportamientos de los grupos (M uchembled: 2002: 10) (Lo destacado en cursivas: D.G.).

Al calco viene esta cita porque en la narrativa de Bolaño se respira este airedeocultamiento, de entramados soterrados del mal, pero quetextualiza -y expone todo el proceso interior que transcurre en los destellos históricos de las novelas, los cuales no dejan dealumbrar, en ningún momento, aunque sean tergiversados, a los de una realidad brutal y aún hoy en el silencio.

Si nos atenemos a la anterior palabra teórica de Muchembled y la vaciamos en la literatura del autor, éste elabora a través de ciertas representaciones imaginarias, por ejemplo, un espacio de interacción colectiva en la historia, que emergió en la década del setenta en Chile: el de una dictadura?. Aquí confluyen varios puertos de definición sobrelos cuales, necesariamente, habrá que detenerse.

En primer término, no resulta objetivo de este ensayo extenderse en el estudio de la dictadura chilena, por demás interpretada bajo una óptica marxista o, por el contrario, fascista. Sólo, a rasgos agigantados, la visualizamos como una transgresión, una ruptura absoluta, respecto a un orden social legítimo, autorizado. Como otros modelos antiguos -el stalinismo- 0 contemporáneos -el régimen argentino, coincidente en el tiempo con el chileno-, esta dictadura se instaura y hace circular sus instancias de enunciados y de prácticas, como las ha denominado Foucault, tendientes a su

${ }^{3}$ Aunque teóricamentemanejado, el concepto dedictadura sesuscribe al deaquel sistema totalitario* en el que"el Estado, conjugando el monopolio del poderío y del sentido, dela violencia física y de la violencia simbólica, de la censura y del adoctrinamiento, busca suprimir todo imaginario social -incluso hasta su recuerdo- que no sea aquel quelegitima y garantiza su poder, y por lo tanto, su influencia en el conjunto de la vida social" (Baczko: 1991: 9). Además, para ampliarlo, resulta interesante pensarlo como "una voluntad singular determinada, [que] al destruir todas las formas de representación política y social, (...) se ha apropiado del poder político en nombre de (...) nuevos valores (...) El resultado de esto es entonces la 'furia de la destrucción'"' (Rosenfield: 1993: 157).

*Como una de las anteriores definiciones hace desgajar el concepto de dictadura del de sistema totalitario, los utilizarécomo sinónimos. También, y como consecuencia, el de régimen totalitario 0 militar. 
imposición, que no excluye, sino que reafirma, la fuerza como uno de sus mecanismos. También el

de determinar las condiciones desu utilización, de imponer a losindividuos (...) un cierto número de reglas y no permitir de esta forma el acceso a ellos, a todo el mundo. (...) [y definir] (...) los comportamientos, las circunstancias (Foucault: 1983: 32-34).

Reglas basadas en la imposición y el reacomodo de la actuación social, son algunas de las variantes que, como diceFoucault, entraman la situación histórica de una dictadura, la cual, per se, introduce la violencia, el ahogo, contra quienes la adversan, acallándolos, maniatando cualquier intento de desconocimiento. Aquí, por supuesto, está el mal como práctica.

Un período histórico donde la invención de representaciones, su legitimidad, se basa en el dominio sobre el espacio colectivo, su legislación práctica y discursiva, y donde, ante cualquier rechazo, actúa el dispositivo de la represión; donde el mal ha encallado. Al respecto, sobran los testimonios, imaginarios culturales de una realidad colectiva, desde películas como La noche de los lápices y La historia oficial, que, aunque denuncias del caso argentino, aprehenden el ambiente deterror implícito en las dictaduras, sobre todo en las latinoamericanas; hasta una canción tan evocadora como "Te recuerdo, Amanda", deV íctor Jara, víctima éste, precisamente, del ejercicio de la fuerza sobre el cuerpo físico y el plano simbólico.

Al ocuparnos deEstrella distantey N octurno deC hile, fundamentalmente, hay que asentar, de entrada, que, en el lenguaje del mal, como su materia, los hechos históricos semejan luces intermitentes, sombras chinescas que proyectan una atmósfera de terror, y quela develan más desdela sugerencia que a partir de la alusión directa. Pero tal perfil no importa: está.

Una de estas luces ilumina, nítidamente, la construcción de la figura de un país, Chile, que se va armando de a poco, entre fragmentos dejados caer al azar. Hay un tiempo histórico que se desliza, subrepticio, reunificándose en palabras cortas, a veces incoherentes, respecto al diálogo o la situación donde se escurre, como si el autor sólo pretendiera esbozar un mapa y no plantear, con la certidumbre ya instituida, los hechos históricos que transcurrieron.

La historia se levanta sobre subtramas, pinceladas de algo que no toma cuerpo, que es, por el contrario, informe. La mimesis de la realidad sobrela palabra creadora, dela que hablaron Auerbach y luego Barthes, ha expirado, y se produce una representación de la cual pudiera dudarse, o, mejor, que no setiene entre las manos porque aparece incompleta. Tanto la forma como el contenido están pespunteados, nunca fueron tejidos con la certeza.

Sucede que a Bolaño no le interesa la historia como "crónica", como "fi- 
liación de la historiografía" (White: 1992: 61-62), lo que consi dera es apropiarse de sus refilones, de al gunos de sus el ementos y pervertirlos, cambiarlos, jugar con ellos, todo dentro del lenguaje del mal. En definitiva, creo, que, para bien, de eso se trata la literatura.

También ocurrequela intencionalidad creadora searmoniza con un gesto que no se puede perder de vista, porque de él viene el centro de nuestro trabajo: el del mal. No colocando sobre un escenario, en este momento, el carácter maligno de la dictadura, sino visualizando el espacio entrecortado queasumen las palabras, las acciones, el repaso de los acontecimientos, dentro de un círculo opresor y acechante.

El lenguaje se hace a semejanza del acontecimiento histórico. Al igual que el ritmo que se le impone a la historia, la escritura se subordina al destello, a la rapidez, al movimiento ágil, y, por supuesto, mientras menos se revele, mejor se resguarda al individuo. Sele pasa por encima al largo fraseo y al minucioso desglose, porque, se sabe, que el silencio, la no mención, constituyen las garantías de permanencia en un régimen totalitario. Además que, dentro deél, ya ha comenzado a subsistir una psicología de la sobrevivencia, la cual se ha unificado, entre otros factores, a partir del no nombramiento, de borrar la relectura de los sucesos históricos que atentan contra la estructura de la nueva autoridad implantada:

Esta identificación (...) constituye una realidad psíquica y es uno de los mejores ejemplos de una ideología convertida en fuerza material.

(...)

La interdependencia (...) entre [lo] individual y [la autoridad] (...), es una de las muchas fuentes de la ideología fascista (Reich: 1980: 78-83).

Como acertadamente señala Reich, y que permite vaciar su apreciación en la escritura de Bolaño, esterápido deseo de saltar el dictado puntual dela historia manifiesta, asimismo, una perspicacia por parte del autor, una psicología pensada, en la dirección de al ejarse para delimitar el peso de la creación literaria respecto al transcurrir histórico, ya que no se trata que el primero imite al último, sino de elaborarlo imaginariamente.

No se presencia un discurso histórico trabajado por la literatura, reitero, como estudió en su momento Hayden White, y como se han ocupado tantas novelas, entre ellas, recientemente, En el tiempo de las mari posas (1995), de Julia Alvarez, y La fiesta del chivo (1999) y El Paraíso en la otra esquina (2003), ambas de M ario Vargas Llosa. En los textos de Bolaño sólo existe el nombramiento fugaz de la historia, una lengua que la bordea, como una especie de contextualidad superficial, pero con alcance.

Mucho se ha dicho sobre el clima de represión, de terror, que impera en un régimen totalitario. Pues bien, Bolaño hatomado al gunos acontecimientos 
históricos, los más revelantes, y los ha vaciado en esta atmósfera, con miedo y cuidado, a través del lenguaje. Es penetrar el propio corazón de una simbología - la del mal- y desde ella, convertirse en

el símbolo (...) de su acción, [en] la noche, donde se pierden las fronteras entre el bien y el mal, la verdad y la mentira.

(...)

... la oscura configuración [del] espíritu (Bilbeny: 1995: 28-39).

Que esta "oscura configuración del espíritu" cierra Nocturno de Chile, por ejemplo, cuando emergen dos frases cuya distinción se renueva, no se sabe si respecto a la dictadura, o, únicamente, al acto creativo del cual se levanta una diatriba en ese contexto (la novela es el largo monólogo de un cura, poeta y crítico literario). La primera parece harto elocuente, o, quizá no: "por qué nos había ocurrido lo que finalmente nos había ocurrido" (Bolaño: 2000: 147). ¿Q ué?, viene al caso preguntarse. Porque la frase está montada sobre una reflexión acerca de la muerte, del olvido, de la literatura, sin embargo, la antecede una hórrida metáfora: "el túnel del tiempo, en la gran máquina de moler carne del tiempo" (147). ¿Acaso la historia, su girar implacable, marcó su huella fatal, demolió un país con su tiempo, como una trituradora? Sería lúcido pensar en esta dirección, pues, más adelante, selee: "Un cadáver que sube desde el fondo del mar o desde el fondo de un barranco" (147), para acabar con la desatada "tormenta de mierda" (150).

Durante la dictadura chilena, el ejercicio de la fuerza condujo, las investigaciones policiales lo han determinado, a ese gran territorio del asesinato y las desapariciones, zona cero dela impiedad y el abuso. Sobre la historia evidente, se escribió la de las sombras, que aún hoy no cesa de envilecerse. Siempre aparecen, como imágenes del espanto, fosas comunes, cadáveres en "el fondo del mar" o "de un barranco", en definitiva, "la tormenta de mierda" (Bolaño: 2000: 150) que arrasó con el tiempo, con la vida, con una nación; y que respondería, en parte, a la interrogante de "por qué nos había ocurrido lo que finalmente nos había ocurrido". En esas frases, todavía esquivas y que pueden prestarse a varios sentidos, se ha ajustado, como una tímida respuesta, una manera de deslizar un cierto juicio - que puede ser o no-, una concatenación con el veloz ensamble de los sucesos históricos que señaléen las citas anteriores de Bolaño. En este sentido del terror palpita el mal, y aunque pareciera minimizado, se agazapa presto a saltar, a no dejarse abatir, puesto que

La violencia (...), muestra en operación una voluntad que, (...) no deja nada en pie. (...) el 'terror' engendró una contradicción entre la universalidad del concepto considerado como regidor de su acción y la singularidad de éste. (Rosenfield: 1993: 156). 
Directamente, este planteamiento de Rosenfield conduce a otra de las prácticas dela lengua del mal en su acepción histórica. Esta zona desilencio y ocultamiento, de supervivencia, va imponiendo, como hilo que se enrolla sobre sí mismo, la insensibilidad.

H ay mucha tela que cortar en este asunto. La raíz del mal se hunde tanto en la práctica de la violencia de la dictadura, como en la alienación para soportarla, y Bolaño ha configurado esta inconsciencia. Resulta interesante admitir quela novela semeja un largo silencio sobre la historia, y quefunda así la gestualidad de la indolencia, la insensibilidad como gesto.

El lenguaje, y no sólo el terror, fue el mejor síntoma de la indolencia social que hizo posible (...) los genocidios. Síntoma y, claro es, agente de transmisión deaquella plaga, la lengua hablada y escrita reflejaba el hundimiento del juicio y estimulaba, simultáneamente, el despliegue inmediato de la acción. La lengua [alcanza] a retratar también, junto con el tumulto del habla, el arrasamiento del juicio moral que crece con el genocidio (...) al servicio del asesinato de masas (Bilbeny: 1995: 36-38) (Lo destacado en cursivas: D.G.).

La insensibilidad envía, fatalmente, un mensaje equívoco a la autoridad del terror: su acción parece respaldada, lo cual, a su vez, recrudeceel despliegue inmediato de la acción, el estímulo al acto brutal que se piensa apoyado. 
Ya aquí ha desaparecido el juicio moral y todo puede ser derribado, apagado, no hay voluntad derespuesta. La sociedad ha caído víctima desu propia trampa: su gesto de sobrevivencia es, al mismo tiempo, el de su condena. Por retrueque, ha quedado al servicio del asesinato de masas, del genocidio.

Por supuesto que el gran inicio de toda dictadura viene en el despliegue del terror. Los allanamientos, las detenciones, y después, la tortura, la humiIlación y la desaparición física representan el vértice de un iceberg de enormes proporciones. Porquetan lacerante como estos actos, y paral el o a ellos, se socava psicológicamente a la sociedad, se la hundeen un estado de anestesia, en el cual se observa y se sabe, pero se calla, y, día tras día, se convierte en cómplice de ese terror que, internamente, rechaza.

Este proceso tiene compleja explicación, y aunque puede desembocar en una catarsis social -como la que permanece simbolizada en el cuerpo de Benito M ussolini, mutilado, colgado por los pies, abierto como una res en el matadero-, la mayoría de las veces el terror seenquista y no halla manera de ser expulsado del espacio social. Continúa profundo sobre su epidermis, como si la hubiera manchado para siempre.

Dos distinciones se desprenden dela reflexión de Bilbeny. El señala hacia la gran figura de las "masas", ese conglomerado anónimo queFoucault analizó como el protagonista de los discursos de exclusión, siempre"silenciosamente allá lejos... (...) enmascarada" (1983: 23). A diferencia de la individualidad a la que Bolaño leencontró rostro en el poeta-torturador Ramírez H offman (La literatura nazi en América y Estrella distante), semira, tanto en la Historia como en la literatura, que el receptor del método violento de la dictadura permanezca sobrecogido detrás del anonimato, de la impersonalidad. En este sentido, las razones varían, y la más terrible, quizá, provenga deesquivar el reconocimiento individual, decreer diluida, en el inconsciente, la responsabilidad del horror en una masa sin rostro.

Tampoco se puede pasar por al to el hecho que estos intervalos de terror, que imponen la complicidad social, entierran a la sociedad en un dilema moral del cual continúa preguntándose por mucho tiempo, fundamentalmente porque, en los casos concretos de Chile y deArgentina, posterior a la desaparición de las dictaduras, se produjo un vínculo de perdón hacia los militares, "el momento en que todos los chilenos debíamos reconciliarnos entre nosotros" (Bolaño: 2000: 141) y, por supuesto, una convivencia social normal y un equilibrio emocional colectivo, parecen incompatibles:

Quéagradable resulta no oír nada. Qué agradable resulta (...) mirar el cielo gris (...) y no tener memoria y sólo escuchar el latido de la sangre. (...). Qué alivio. Quésilencio. Quépaz (Bolaño: 2000: 71).

Aquí se arriba a un punto importante: en la indiferencia frente al terror, habita el mal. Setrata dever la primera como una delas ramificaciones-quizá 
la principal- con la que, después de Auschwitz, ha brotado el mal en el siglo $X X$, y que ahora continúa, florecida, además, por el hedonismo, el placer desmedido, las incertezas históricas. La insensibilidad ha desbrozado las vías para que el mal semeje una forma vacua, un universo donde el sujeto ha penetrado sin reconocerlo. Las matanzas entreárabes y judíos que la tel evisión reproduce casi a diario no generan mayor grado de angustia que cualquier caso de banal crónica roja. El mal seha encerrado -y es una paradojaen el gesto de la sobrevivencia, en un resguardo ilusorio de la "integridad".

Si no, ¿cómo explicar tanto silencio frente a la tortura, a la muerte violenta? El mal se ha apoderado de la angustia y sin ella la sociedad aísla el dolor. Hay una coraza ante el cadáver que aparece desnudo y torturado en cualquier calle, frente al drama de los desaparecidos, de los niños arrebatados a sus padres. "Son otros", parece gritar esa propia sociedad, excluyéndose del acto que, en su inconsciente colectivo, sabe que le pertenece, porque todos sus miembros pueden aparecer, desnudos y torturados, en cualquier calle. El mal está más en el hastío social que en su propia naturaleza hórrida.

Precisamente, Nocturno de Chile descubre, en un lenguaje de breves intermitencias, esta insensibilidad colectiva:

... ¿por quénadie, en su momento, dijo nada? La respuesta era sencilla: porque tuvo miedo, porque tuvieron miedo. (...). ¿Para quéremover lo que el tiempo piadosamente oculta? (...) un tiempo diacrónico en donde se sucedían escenas incomprensibles, tristes, lejanas. (...) un gesto que denotaba a partes iguales cansancio y hastío, (...). ¿Usted sabía todo lo que hacía Jimmy? Sí, padre. ¿Y searrepiente? Igual quetodos, padre. (...). A veces yo estaba viendo la tele con los niños y se iba la luz por un rato. No oíamos ningún grito, sólo la electricidad que se iba de gol pe y después volvía (Bolaño: 2000: 144-146) ( $L$ o destacado en cursivas: D.G.).

La indolencia pone sobre la mesa la alegoría oculta de la dictadura: detenciones, tortura, atropellos. Nunca será vano repetir su relato más completo, porque, lacerante, se sobrepone en él la poesía del horror.

Cuando esta historia, "Había toque de queda. Los restaurantes, los bares cerraban temprano. La gente se recogía a horas prudentes" (Bolaño: 2000: 124) y, por supuesto, "No había muchos lugares donde se pudieran reunir los escritores y los artistas a beber y hablar hasta que quisieran" (124); entonces, "La historia, la verdadera historia, (...) simple y cruel" (124) dice de un pesado silencio, donde "nadie, en su momento, dijo nada" (142). M aría Canales, la poeta, "era buena moza, era joven (...) tenía cierto talento" (124125), "tenía dos hijos pequeños, (...) y estaba casada con un norteamericano Ilamado James Thompson (...) al que (...) Ilamaba Jimmy" (126). Su casa "en los confines de Santiago" (140), "en las afueras (...), rodeada por un jardín lleno deárboles" (125), con "un esplendor nocturno eimpune" (143), 
y donde "la gente se sentía bien en las veladas o tertulias" (126) se transfigura, sobre su espacio "confortable", sobre "el canto de los pajarillos en el jardín" (128), en el precipicio del terror: en ella, "Los subversivos pasaban por los sótanos (...), en donde [Jimmy] los interrogaba, les extraía toda la información posible, (...). En su casa, por regla general, no se mataba a nadie. Sólo se interrogaba, aunque al gunos murieron" (141). "Aquí mató un empleado de immy al funcionario español dela U NESCO. Aquí mató Jimmy a la Cecilia Sánchez Poblete" (146), porque

Jimmy Thompson había sido uno de los principales agentes de la DINA (...) que usaba su casa como centro de interrogatorios. (...).

También se supo que immy había viajado aWashington y había matado a un antiguo ministro de Allende y de paso a una norteamericana. Y que había preparado atentados en Argentina contra exiliados chilenos e incluso algún atentado en Europa (Bolaño: 2000: 141).

A esta revelación le sigue una frase que queda marcada como una letra escarlata: "Eso sesupo" (Bolaño: 2000: 141). Seestáaceptando el hecho oculto, el que se suponía a sotte voce después de un incidente en el sótano, pero, ni así, se traspasa el espeso muro del silencio.

La historia se endurece como una piedra, pero todavía más, por la constatación antela indiferencia de quienes, al guna vez, borrachos, se perdieron en esos sótanos y vieron "al hombre atado a una cama metálica, los ojos vendados, (...) alguien a punto de morir" (Bolaño: 2000: 140), y "[ cerraron] delicadamente la puerta, (...), apagando a sus espaldas las luces que previamente había[n] encendido" (141). Y callaron - peor, ni siquiera trataron de socorrer al hombre- "'Y meses después, o tal vez años después, otro habitual de las veladas me contó la misma historia. Y luego otro y luego otro y otro más. Y luego llegó la democracia" (141). ¿Se puede vivir conscientemente con el peso de esta historia? Parece que sí, pues se trata

de dormir la conciencia y la emoción a la vez. (...). El siglo XX ha descubierto que la maldad es cosa de pura rutina, para lo cual sólo hay que anestesiar el sentimiento. (...) [jamás] reflexionar, decidir, zafarse, en definitiva, de la propia indolencia (Bilbeny: 1995: 57-59).

Pero el colmo de la indiferencia viene en una voz que afirma: "Vetetranquilo" (Bolaño: 2000: 139). Porquela historia pudo haberseclarificado cuando la persona que descubre al torturado, "se lo contó a un amigo y éste selo contó a mi amigo, quien (...) melo contó a mí. Su conciencia lo mortificaba. Vete tranquilo, le dije" (139) (Lo destacado en cursivas: D.G.), y el hecho queda impune. M as existe algo peor, sí, todavía peor: por un momento, el último involucrado comenta: "Yo hubiera podido decir algo, pero yo nada vi, nada supe hasta que fue demasiado tarde" (142) , jfalsa afirmación!, pues, 
anteriormente, se decía dueño de "la historia, la verdadera historia" (124). Además, esta confesión se afianza con una serie de acotamientos de tiempo: "M ás tarde, ¿cuánto más tarde?" (139), "mucho más tarde" (139), ¿acaso esto importa frente al crimen? Un juego de manipulación para una verdad única: el silencio ante

la cama metálica. (...). Sobre el catre había un hombre desnudo, atado de las muñecas y de los tobillos. Parecía dormido, pero esta observación es difícil de verificar, pues una venda le cubría los ojos. El extraviado (...) cerró la puerta, (...) , y descorrió sigilosamente el camino andado. Cuando llegó a la sala (...) no dijo nada (Bolaño: 2000: 139).

Y es más dolorosa - de tan cínica- la frase que continúa esta cita: "H abía cerrado la puerta sigilosamente, procurando no despertar al pobre hombre que reparaba en el sueño su dolor" (Bolaño: 2000: 140). Hay una absoluta impiedad en la indiferencia, una bestialidad inclemente con la condición humana. El mal en su esencialidad más pura.

Tanta indiferencia agrede. Como se sabe, lo que no impacta, jamás compromete, y esto resulta válido tanto para el individuo o la sociedad que sabe -y calla-, como para quien ejecuta el acto. Ambos se encuentran en un mismo nivel de lejanía y han anestesiado sus sentimientos. Uno, cómplice; el otro, criminal, sin embargo, sus conductas reproducen una anormalidad psicopática, para Bilbeny "una desviación" (1995: 121) en sus sentimientos queles impide renunciar al mal, zafarse deél.

Por este sentido, se desliza el lenguaje de Bolaño, apuntalando vacíos, susurros, entrecortamientos, indiferencia, moldeándose como la materia abyecta de este hastío. Le ha dado voz al mal, una voz, paradójicamente, de silencio, muda, como será siempre la que impone el terror.

El autor ha jugado con la realidad histórica. De ella toma elementos, los maneja satíricamente, se ríe de ellos. Así, acentúa la elaboración imaginaria de la historia a través de la irreverencia más absoluta, la decapita bajo la sonrisa inconmovible del verdugo. En este discurso cabe la idea de White acerca de que la narrativa que asume acontecimientos históricos

se compone no de un único código monolíticamente utilizado, sino de un complejo conjunto de códigos cuya interrelación por parte del autor - para la producción de una historia infinitamente rica en sugerencias y tonalidades alectivas, por no decir de actitudes y evaluaciones subliminales de su objeto- da fe de su talento como artista, (...) más que como siervo de los códigos disponibles en el momento (1992: 59).

A través de esta cita, aclaro que la realidad histórica chilena únicamente encanta a Bolaño con al gunas voces, con ciertos referentes que, a su antojo, enriquecen el lenguaje del horror, que resulta, en definitiva, su premisa de 
construcción literaria. Ni siquiera la última frase de la narración: “Y después se desata la tormenta de mierda" (Bolaño: 2000: 150), alude directamente al torrente hórrido de la historia chilena, sino que permanece como el vórtice donde las vidas de los protagonistas - poetas, religiosos, militares, todos vanos nombres- caen, irremediablemente. Porque la historia quedó atrás, no interesa; 0, mejor, porque, dentro de ella, fue siempre el grito "que (...) nadie (...) escuch[ó]" (149-150).

En una última instancia, encuentro una cita en Nocturno de Chile que merece atención, ya que, en sí misma, compacta, con la mirada del desgano, el estado moral de una sociedad bajo la dictadura militar:

... la vida seguía y seguía y seguía, como un collar de arroz en donde cada grano llevara un paisaje pintado, granos diminutos y pai sajes microscópicos, y yo sabía que todos se ponían el collar en el cuello pero nadie tenía la suficiente paciencia o fortaleza deánimo como para sacarseel collar y acercárselo a los ojos y descifrar grano a grano cada paisaje, en parte porque las miniaturas exigían vista de lince, vista deáguila, en parte porque los pai sajes solían deparar sorpresas desagradables como ataúdes, cementerios a vuelo de pájaro, ciudades deshabitadas, el abismo y el vértigo, la pequeñez del ser y su ridícula voluntad, gente que mira la televisión, gente que asiste a los partidos de fútbol, el aburrimiento como un portaaviones gigantesco circunnavegando el imaginario chileno. Y ésa era la verdad (Bolaño: 2000: 123) (Lo destacado en cursivas: D.G.).

Estas palabras recogen todo el hastío posible, cómo una sociedad se sacude de su conciencia, para no enfrentar lúcidamentelos pai sajes desagradables, esos de la muerte: cadáveres en basureros, calles solitarias, toque de queda, impunidad y crimen. Una sociedad que sólo habita en el espacio de la televisión y el fútbol, evadiéndose, huyendo. Pequeña en su voluntad, ha permitido sobre su cuello el collar del horror, y le falta fortaleza para arrancárselo. No hay dudas: "La apatía es un síntoma de muerte que acaba también con el cuerpo o lo devuelvea un estadio evolutivo más bajo" (Bilbeny: 1995: 60).

\section{ACOTANDO}

Regreso otra vez al punto de partida de este análisis. Bolaño construye un lenguaje del mal con situaciones históricas como las que recoge la cita anterior, con ese nocturno aterrador de Chile, y juega a codificarlas con metáforas, con una niebla de vaguedad o de silencio, subversivamente.

Sobre los personajes y las situaciones de La literatura nazi en América, Estrella distante, Amuleto y N octurno de Chilese expandeuna bruma de has- 
tío, dehorror. Son lasnovelas escritas por ese "siniestro batallón que M acbeth capitanea (...) hoy en los miles y miles de seres apáticosque no sienten nada frente al dolor (...) delos demás" (Bilbeny: 1995: 128).

En definitiva, para Bolaño, como en el verso de Rimbaud, "Ninguna fe en la historia, olvido de los principios. Callaré" (1989: 71).

BiBLIOGRAFÍA

Arendt, Hannah. 1992. Hombres en tiempos de oscuridad. Barcelona: Gedisa.

Auerbach, Erich. 1986. M ímesis. La Habana: Arte y Literatura.

Baczko, Bronislaw. 1991. Los imaginarios sociales. Buenos Aires: Ediciones Nueva Visión.

Bajtín, M ijail. 1986. Problemas literariosy estéticos. La Habana: Editorial Artey Literatura.

Barthes, Roland. 1967. "Le discours del'histoire”, en: Social Science Information. París. . 1980. El grado cero de la escritura. M éxico: Siglo XXI.

Baudrillard, Jean (1997). La transparencia del mal. Ensayo sobrelosfenómenos extremos. Barcelona: Anagrama.

Bilbeny, Norbert (1995). El idiota moral. La banalidad del mal en el siglo XX. BarceIona: Anagrama.

Bolaño, Roberto. 1996a. La literatura nazi en América. Barcelona: Seix Barral. . 1996b. Estrella distante. Barcelona: Anagrama. 1999. Amuleto. Barcelona: Anagrama. 2000. N octurno de Chile. Barcelona: Anagrama.

Foucault, M ichel. 1983. El orden del discurso. Barcelona: Tusquets Editores.

Lévi-Strauss, Claude. 1975. El pensamiento salvaje. M éxico: Fondo de Cultura Económica.

Muchembled, Robert. 2002. Historia del diablo. M éxico: Fondo de Cultura Económica.

Reich, Wilhelm. 1980. Psicología de masas del fascismo. Barcelona: Bruguera.

Rimbaud, Arthur. 1989. Poesía de Rimbaud. La Habana: Arte y Literatura.

Rojas, Sergio. 2000. “Cuerpo, lenguaje y desaparición”, en: Richard, Nelly (edit.). Políticas y estéticas de la memoria. Chile: Cuarto Propio.

Rosenfield, D enis L. 1993. Del mal. Ensayo para introducir en filosofía el concepto del mal. M éxico: Fondo de Cultura Económica.

White, Hayden. 1992. El contenido de la forma: narrativa, discurso y representación histórica. Barcelona: Paidós.

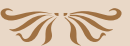


